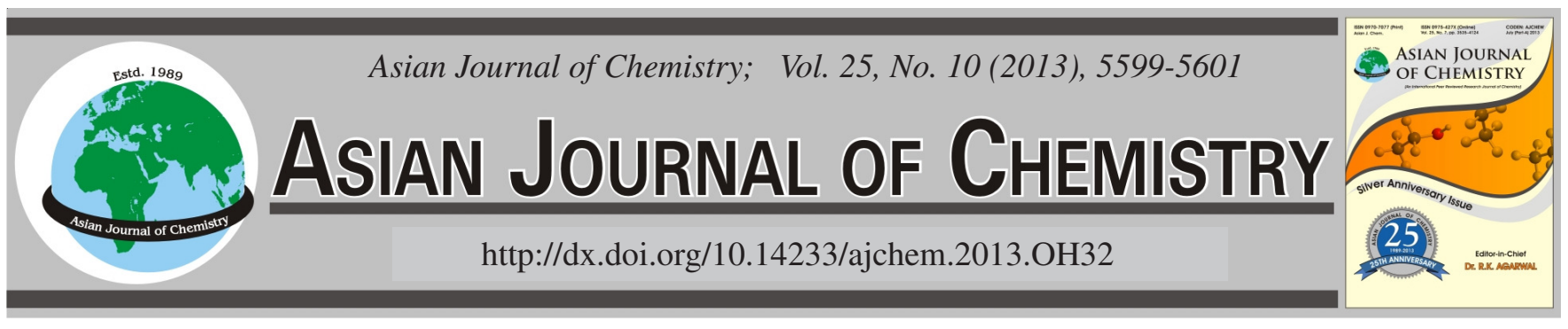

\title{
Determination of Mercury in Various Environmental Samples in 2012 $\dagger$
}

\author{
Lakshmi Narayana Suvarapu*, Young-Kyo SeO and Sung-OK Baek
}

Department of Environmental Engineering, Yeungnam University, Gyeongsan-si 712 749, Republic of Korea

*Corresponding author: E-mail: suvarapu@gmail.com

This paper discusses the determination of mercury in different biological and environmental samples with various analytical techniques, such as atomic absorption spectroscopy, spectrophotometer, voltammeter, inductively coupled plasma techniques, Spectrofluorometer and HPLC/GC reported by the researchers worldwide during 2012.

Key Words: Mercury, Analytical methods, Environmental and biological samples.

ᄂ _ - - - - - - - - - - - - -

\section{INTRODUCTION}

Mercury is the only metal in the periodic table exists in liquid state at standard temperature and pressure values. Mercury and its compounds mostly used in fluorescent lamps, thermometers and as electrodes. Due to its toxicity to humans in most cases it is replaced with others like Galinstan ${ }^{1}$. Mercury, commonly exist in three oxidation states i.e., 0 (metallic mercury), +1 (mercurous compounds) and +2 (mercuric/ organomercury compounds). In high enough doses all forms of mercury are toxic ${ }^{2}$. The toxicity of mercury depends on the solubility of their compounds, those which are soluble and volatile will became hazardous to human body and causes many adverse effects. The chronic mercury poisoning in children causes the disease called Acrodynia or pink disease ${ }^{3}$. One of the most tragedic incidents regarding the mercury poisoning was observed in 1956 at Minamata bay of Japan and named the disease as Minamata disease, which induced the symptoms like numbness in the hands and feet, damage to hearing and speech. It may also cause paralysis, coma and death in extreme conditions ${ }^{4}$. The hazardous nature of mercury attracts so many researchers to found its concentration in various environmental matrices like water ${ }^{5-6} \operatorname{soil}^{7}$ and air ${ }^{8}$ by using different analytical techniques.

So many authors reviewed the reported concentration of mercury and/or methylmercury in various environmental matrices with different analytical techniques. Leopold et al. ${ }^{9}$ reviewed for the determination and speciation of mercury, but it was limited only to natural waters. Pandey et al. ${ }^{10}$ reviewed the measurement techniques for mercury in ambient air.
Recently, Cheng and $\mathrm{Hu}^{11}$ reviewed the mercury in municipal solid waste in China. A lot of importance was given in recent years for the determination and speciation of mercury by the researchers in all over the world. This forces us to review the determination of mercury in various environmental matrices with different analytical techniques reported during 2012.

We reviewed the published research papers during 2012 in international journals regarding the determination of mercury with various analytical techniques. All the information of these reviewed papers is presented in Table- 1 . The literature survey reveals the need of accurate and precise methods for the determination of mercury in various environmental matrices. Most of the researchers determined the total mercury, but it is very important to determine the methylmercury due to its toxicity. This review predicts the need of speciation studies of mercury in future.

\section{REFERENCES}

1. P. Surmann and H. Zeyat, Anal. Bioanal. Chem., 383, 1009 (2005).

2. J.C. Clifton II, Pediatric Clinics of North America, 54, 237 (2007).

3. G. Bjorklund, J. Orthomol. Med., 10, 145 (1995).

4. http://en.wikipedia.org/wiki/Minamata_disease

5. A.S. Yazdi, S. Banihashemi and Z. Eshaghi, Chromatographia, 71, 1049 (2010).

6. D. Saniewska, M. Beldowska, J. Beldowski, M. Saniewski, J. Kwasniak and L. Falkowska, J. Environ. Sci., 22, 1144 (2010).

7. C. Gil, R. Miras, L.R. Perez and R. Boluda, Chemosphere, 78, 409 (2010).

8. A.S. Brown, R.J.C. Brown, M.A. Dexter, W.T. Corns and P.B. Stockwell, Anal. Methods, 2, 954 (2010).

9. K. Leopold, M. Foulkes and P. Worsfold, Anal. Chim. Acta, 663, 127 (2010).

10. S.K. Pandey, K.H. Kim and R.J.C. Brown, Trends Anal. Chem., 30, 899 (2011).

11. H. Cheng and Y. Hu, Environ. Sci. Technol., 46, 593 (2012). 
TABLE-1

SUMMARY OF THE PUBLISHED PAPERS REGARDING DETERMINATION OF MERCURY IN 2012

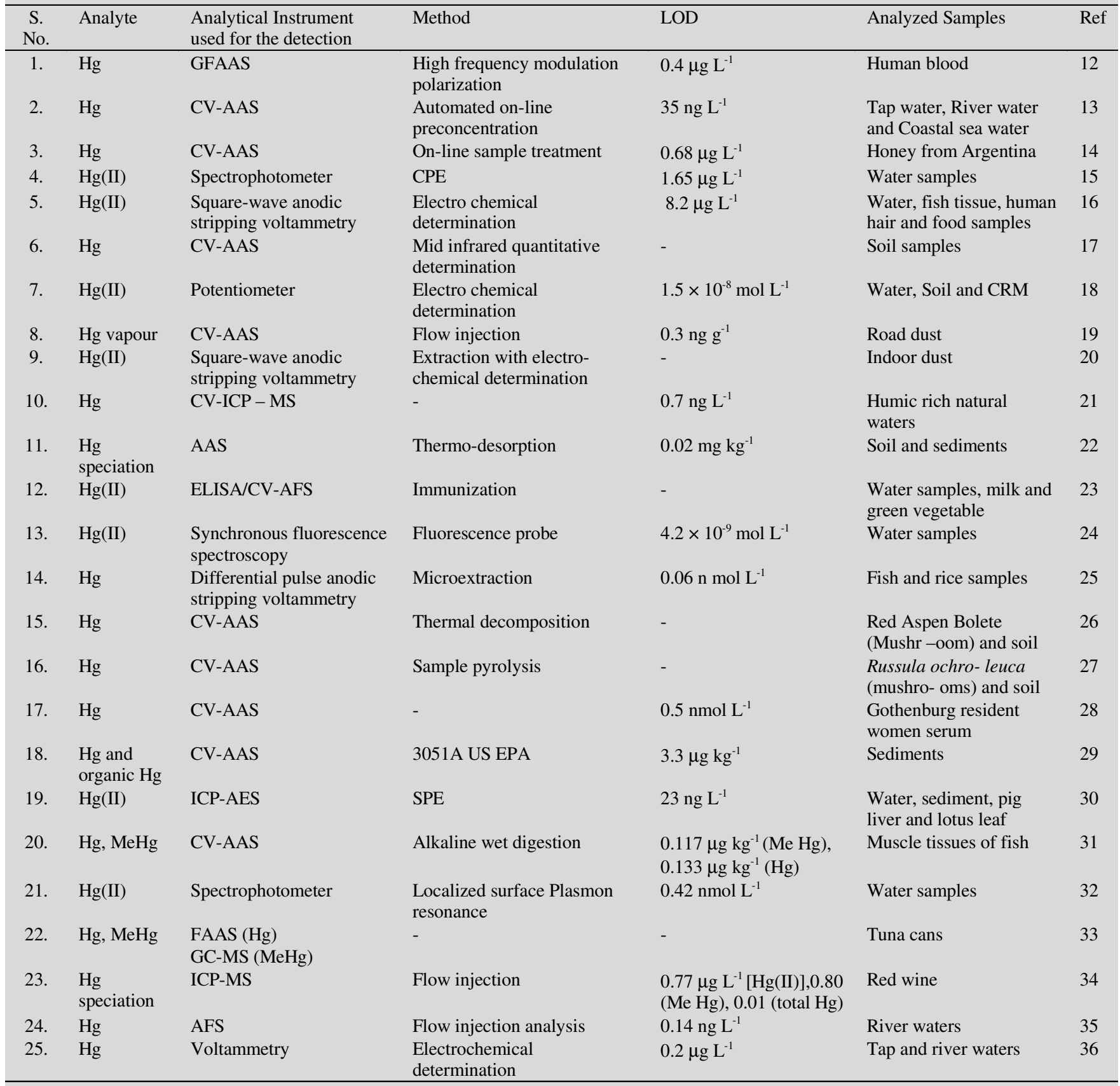

GFAAS: Graphite furnace atomic absorption spectroscopy; CV-AAS: Cold-vapour atomic absorption spectroscopy; CPE: Cloud point; Extraction; ELISA: Enzyme-linked Immunosorbent assay; CRM: Certified reference materials; AFS: Atomic fluorescence spectroscopy; SPE: Solid phase extraction

12. N.B. Ivanenko, N.D. Solovyev, A.A. Ivanenko and A.A. Ganeev, Achieves Environ. Contamination Toxicol., 63, 299 (2012).

13. M. Puanngam, P.K. Dasgupta and F. Unob, Talanta, 99, 1040 (2012).

14. M.A. Dominguez, M. Grunhut, M.F. Pistonesi and M.S. Di Nezio, $J$ Agric. Food Chem., 60, 4812 (2012).

15. H.I. Ulusoy, R. Gurkan and S. Ulusoy, Talanta, 88, 516 (2012).

16. A. Afkhami, T. Madrakian, S.J. Sabounchei, M. Rezaei, S. Samiee and M. Pourshahbaz, Sens. Actuators B, 161, 542 (2012).

17. S.R. Jean-Philippe, N. Labbe, J.A. Franklin and A. Johnson, Proceed. Int. Acad. Ecol. Environ. Sci., 2, 139 (2012).

18. F. Aboufazeli, H.R.L. Zadeh Zhad, V. Amani, E. Najafi, O. Sadeghi and N. Tavassoli, J. New Mater. Electrochem. Syst., 16, 41 (2013).

19. A. Londonio, F. Fujiwara, R.J. Rebagliati, D. Gomez and P. Smichowski, Microchem. J., 105, 77 (2012)
20. E. Bernalte, C.M. Sanchez and E.P. Gil, Talanta, 97, 187 (2012)

21. H. Pyhtila, P. Peramaki, J. Piispanen, M. Niemela, T. Suoranta, M. Starr, T. Nieminen, M. Kantola and L. Ukonmaanaho, Microchem. J., 103, 165 (2012).

22. A.T. Reis, J.P. Coelho, S.M. Rodrigues, R. Rocha, C.M. Davidson, A.C. Duarte and E. Pereira, Talanta, 99, 363 (2012).

23. Y. Wang, H. Yang, M. Pschenitza, R. Niessner, Y. Li, D. Knopp and A. Deng, Anal. Bioanal. Chem., 403, 2519 (2012).

24. Y.Q. Wang, Y. Liu, X.W. He, W.Y. Li and Y.K. Zhang, Talanta, 99, 69 (2012).

25. A.A. Ensafi, A.R. Allafchian, M. Saraji and B. Farajmand, Talanta, 99, 335 (2012)

26. J. Falandysz, I. Kowalewska, I.C. Nnorom, M.Drewnowska and G. Jarynska, J. Environ. Sci. Health Part A, 47, 1695 (2012). 
27. M. Drewnowska, A. Sapor, G. Jarzynska, I.C. Nnorom, K.S. Sajwan and J. Falandysz, J. Environ. Sci. Health Part A, 47, 1577 (2012).

28. I.A. Bergdahl, M. Ahlqwist, L. Barregard, C. Bjorkelund, A. Blomstrand, S. Skerfving, V. Sundh, M. Wennberg and L. Lissner, Int. Achieves Occupat. Environ. Health, 86, 71 (2012).

29. R.L. Franklin, J.E. Bevilacqua and D.I.T. Favaro, Quim. Nova, 35, 45 (2012).

30. Y. Jiang, H. Zhang, Q. He, Z. Hu and X. Chang, Microchim. Acta, 178, 421 (2012).

31. A.Q. Shah, T.G. Kazi, J.A. Baig, H.I. Afridi and M.B. Arain, Food Chem., 134, 2345 (2012).
32. N. Bi, Y. Chen, H. Qi, X. Zheng, Y. Chen, X. Liao, H. Zhang and Y. Tian, Sens. Actuators B, 166-167, 766 (2012).

33. J. Salaramoli, N. Salamat, Sh. Najafpour, J. Hassan and T. Aliesfahani, World Appl. Sci. J., 16, 577 (2012).

34. V.L. Dressler, C.M.M. Santos, F.G. Antes, F.R.S. Bentlin, D. Pozebon and E.M.M. Flores, Food Anal. Methods, 5, 505 (2012).

35. K. Leopold, A. Zierhut and J. Huber, Anal. Bioanl. Chem., 403, 2419 (2012).

36. D.M. Yerga, M.B.G. Garcia and A.C. Garcia, Sens. Actuators B, 165, 143 (2012) 